\title{
PERAN INOVASI KONSUMEN DALAM MENCIPTAKAN NIAT BERPERILAKU (Survei Pada Konsumen SFA Steak \& Resto Surakarta)
}

\section{THE ROLE OF CONSUMER INNOVATION IN CREATE BEHAVIORAL INTENTION (Survey on SFA Steak \& Resto Consumers in Surakarta)}

\author{
Oleh: \\ Lamidi 1) dan Marjam Desma Rahadhini ${ }^{2)}$ \\ ${ }^{1,2)}$ Fakultas Ekonomi Universitas Slamet Riyadi Surakarta \\ e-mail: ${ }^{1)}$ lamidi71@ gmail.com \\ 2)
}

\begin{abstract}
This study aims to analyze the influence of consumer innovation with several factors that determine behavioral intention. This study determine the importance of consumer innovation, consumer gratitude, the image of a restaurant in innovation, and the price fairness as a mediating variable. This research is a survey and data collection using a questionnaire. The population is consumers in the Surakarta. The sample is determined as 130 respondents with convenience sampling, namely consumers who make purchases at SFA Steak \& Resto Surakarta. Validity testing uses Confirmatory Factor Analysis (CFA), and Cronbach's Alpha for reliability testing. Data analysis using Structural Equation Model (SEM) with Amos. The research findings show consumer innovation influences restaurant gratitude and image, but does not affect price fairness; consumer gratitude on the price fairness and behavioral intention; restaurant image influences the price fairness and behavioral intention; the price fairness does not affect behavioral intention. Research implications should SFA Steak \& Resto Surakarta need to consider making new menus to make consumers more varied in choice, besides that employees need to thank after providing services to consumers.

Keywords: consumer innovation, consumer gratitude, price fairness , restaurant image, and behavioral intention
\end{abstract}

\begin{abstract}
Abstrak
Penelitian ini bertujuan menganalisis pengaruh inovasi konsumen dengan beberapa faktor yang menjadi penentu niat berperilaku konsumen. Penelitian ini berupaya mengetahui pentingnya inovasi konsumen, dengan mempertimbangkan rasa terima kasih konsumen, citra restoran dalam berinovasi, dan kewajaran harga sebagai variabel mediasi. Penelitian ini merupakan survei. Pengumpulan data menggunakan kuesioner. Populasi penelitian adalah konsumen di wilayah Surakarta. Sampel ditentukan sebanyak 130 responden dengan metode convenience sampling, yaitu konsumen yang melakukan pembelian di SFA Steak \& Resto Surakarta. Pengujian validitas menggunakan Confirmatory Factor Analysis (CFA), dan Cronbach's Alpha untuk uji reliabilitas. Analisis data menggunakan Structural Equation Model (SEM) dengan program Amos. Temuan penelitian menunjukkan bahwa inovasi konsumen berpengaruh terhadap ucapan terima kasih dan citra restoran, tetapi tidak berpengaruh terhadap kewajaran harga; ucapan terima kasih berpengaruh terhadap kewajaran harga dan niat berperilaku; citra restoran berpengaruh terhadap kewajaran harga dan niat berperilaku; kewajaran harga tidak berpengaruh terhadap niat berperilaku. Implikasi penelitian hendaknya SFA Steak \& Resto Surakarta perlu mempertimbangkan pembuatan menu-menu baru supaya semakin variatif pilihan konsumen, selain itu karyawan perlu mengucapkan terima kasih setelah memberikan pelayanan kepada konsumen.

Kata kunci: inovasi konsumen, rasa terima kasih, kewajaran harga, citra restoran, dan niat berperilaku
\end{abstract}


PENDAHULUAN

Setiap perusahaan dalam menghasilkan produk dituntut mengerti dan memahami keinginan konsumen dengan konsep fokus pada konsumen (costumer focused) atau berorientasi pasar (market oriented culture) untuk tetap dapat mengakses pasarnya secara menguntungkan dan menjamin pertumbuhan secara berkelanjutan serta unggul dalam persaingan (Sukarmen, Sularso dan Wulandari, 2013). Keunggulan bersaing dapat berasal dari aktivitas perusahaan seperti dalam mendesain, memproduksi, memasarkan, menyerahkan, dan mendukung produknya. Restoran dirancang untuk menyediakan makanan yang berkualitas, layanan dan suasana yang unggul bagi konsumen (Hyun dan Kang, 2014). Salah satu strategi retensi pelanggan yang digunakan restoran adalah dengan memberikan penawaran menu baru dan inovatif secara konsisten. Restoran menggunakan pendekatan inovatif untuk pengembangan menu dan pengiriman layanan yang lebih cepat apabila dibandingkan dengan makanan cepat saji (Lane, 2013). Hal tersebut dilakukan karena restoran mengandalkan pada menu makanan yang lezat sehingga membutuhkan inovasi dengan melakukan inovasi produk.
Penelitian ini fokus untuk memahami pentingnya efek inovasi konsumen terhadap restoran dan potensi konsumen dengan beberapa faktor yang menjadi penentu niat berperilaku konsumen. Penelitian ini berupaya mengetahui tentang pentingnya inovasi konsumen dan perilaku restoran dalam berinovasi dengan mempertimbangkan variabel kewajaran harga. Kewajaran harga menjadi salah satu faktor penentu keputusan untuk melakukan pembelian ulang (Daskalopoulou, 2008) dan menjadi pendorong utama perilaku masa depan (Diller, 2008). SFA Steak \& Resto juga melakukan inovasi produk untuk membuat konsumen memiliki alternatif atau variasi menu yang beragam, diantaranya adalah promo baru SFA Steak \& Resto semua menu cuma 5 ribu untuk beberapa jenis produk. Selain itu pada akhir tahun 2018 SFA Steak \& Resto mengeluarkan menu baru yaitu Yaps Fried Chicken dengan harga Rp 9.500, dan mengeluarkan paket promosi bagi yang ulang tahun, serta memberikan promo bagi produk makanan tertentu. SFA Steak \& Resto merupakan restoran yang mengedepankan inovasi produk maupun inovasi restoran untuk memperoleh image yang baik dari konsumen sehingga membuat konsumen melakukan pembelian ulang kembali. Penelitian ini dilakukan di SFA Steak \& 
Resto yang ada di wilayah Surakarta. SFA Steak \& Resto berdiri sejak tahun 2005 dan terus mengembangkan diri untuk memberikan pelayanan terbaik dengan mendasarkan pada nilai-nilai SFA yaitu Pelayanan Terbaik, Kualitas Tinggi, Integritas Tinggi, Inovatif dan Kerjasama.

\section{TINJAUAN PUSTAKA}

\section{Inovasi Konsumen}

Inovasi konsumen didefinisikan sebagai kecenderunga individu untuk merangkul ide-ide baru atau unik, produk, dan layanan (Özoğlu dan Bülbül, 2013). Konsumen yang inovatif didefinisikan sebagai kelompok konsumen yang relatif kecil, yang merupakan pembeli awal produk baru tertentu. Konsumen yang inovatif selalu mencari informasi mengenai minat khusus mereka dari berbagai sumber informal dan media massa (Hartini, 2011). Mayoritas konsumen pada dasarnya cenderung menolak inovasi dan atau adopsi produk baru, oleh karena itu menarik konsumen yang inovatif sangat penting untuk kesuksesan produk dan layanan baru.

Consumer innovativeness adalah sifat yang melekat pada individu, individu yang suka menjadi orang pertama yang membeli sesuatu barang/jasa baru. Konsumen innovator biasanya menjadi pemimpinpendapat (opinion leader), mereka banyakmemberi informasi dan nasehat terkait kepada konsumen lain mengenai produk baru. Konsumen yang innovatif biasanya antusias mengenai produk baru serta mendorong orang lain untuk mencobanya. Beberapa sifat yang melekat pada keinovasian konsumen antara lain: 1) kurang dogmatis (cenderung menerima produk baru atau yang belum dikenal dengan keterbukaan yang besar dan sedikit kekahawatiran, 2) inovator cenderung self oriented, mengandalkan standar atau nilai mereka sendiri ketika mengambil keputusan, 3) cenderung berani mengambil resiko mencoba berbagai produk baru (Hartini, 2011). Konsumen yang inovatif menikmati kreativitas penjelajahan, secara intrinsik ingin tahu, dan memiliki kegemaran untuk mengambil risiko (Choo et al., 2014). Konsumen yang inovatif relatif lebih banyak mungkin merangkul menu dan layanan baru (Englis dan Phillips, 2013), dan konsumen yang inovatif akan memberikan penghargaan untuk perusahaan yang dianggap sebagai inovator yang efektif, serta secara emosi memberikan keuntungan bagi perusahaan karena adanya niat 
mengunjungi kembali (Hwang dan Hyun, 2013), Hal ini membuat inovasi konsumen merupakan konstruksi yang cukup penting untuk pemilik restoran yang akan mempengaruhi kewajaran harga, terima kasih dan reputasi restoran untuk inovasi.

\section{Kewajaran harga}

Kewajaran harga adalah sejauh mana konsumen percaya bahwa harga yang ditetapkan untuk produk atau layanan tertentu adalah sah dan dapat dibenarkan (Xia dan Monroe, 2010). Nazari et al., (2014) mengatakan kewajaran harga begitu penting dalam keberhasilan meningkatkan harga produk. Harga merupakan salah satu faktor penentu untuk kepuasan pelanggan, dan mempengaruhi loyalitas, hal ini karena pelanggan sering khawatir tentang kewajaran harga, terutama untuk harga tinggi.

Consuegra et al. (2007) mendefinisikan kewajaran harga sebagai suatu penilaian untuk suatu proses sehingga menciptakan hasil yang masuk akal dan dapat diterima. Aspek ini menunjukkan bahwa penilaian kewajaran harga melibatkan perbandingan prosedur harga yang terkait dengan standar, proses, nilai, referensi dan norma. Dhurup, et al., (2014) dikatakan bahwa niat beli konsumen salah satunya dipengaruhi oleh harga yang wajar (fair), misalnya kewajaran dari sisi nilai produk, kualitas, brand, keterjangkauan, dan manfaat yang ingin ditawarkan melalui harga yang ada. Konsumen sering tidak mau membayar harga yang tidak wajar. Kewajaran harga dapat menjadi salah satu bahan pertimbangan konsumen dalam proses pengambilan keputusan pembelian bahkan menciptakan peluang untuk membangun loyalitas konsumen (Sugiama, 2017).

Konsumen menentukan kewajaran harga dengan menganalisis beberapa faktor seperti harga yang dibayarkan sebelumnya, standar pasar terhadap harga yang dipasang, dan transparansi harga (Homburg et al., 2014). Penilaian ketidakadilan biasanya disebabkan ketika konsumen merasa bahwa mereka ditempatkan pada kerugian ekonomi berhadapan dengan harga yang dibebankan (Xia dan Monroe 2010).

\section{Ucapan Terima kasih}

Ucapan terima kasih adalah sentimen positif yang diungkapkan oleh seorang individu ketika dia merasakan bahwa suatu tindakan yang dilakukan oleh orang lain atau entitas lain telah menguntungkannya (Palmatier et al., 
2009). Rasa terima kasih ini dianggap sebagai atribut universal yang tertanam dalam jalinan sifat manusia, meresapi pemikiran dan tindakan individu (Emmons and Stern, 2013). Di luar ekspresi emosional yang positif, rasa terima kasih bisa dikonseptualisasikan sebagai kekuatan pendorong di belakang yang mendukung aktivitas individu (Palmatier et al. 2009). Kim dan Lee (2013) mengidentifikasi bahwa rasa terima kasih berkontribusi signifikan di dalam meningkatkan retensi pelanggandan meningkatkan loyalitas pelanggan, karena restoran pelu bekerja dengan strategi yang baik dalam upaya meningkatkan rasa terima kasih dari konsumen dalam upayanya membentuk hubungan dengan pelanggan yang kuat.

\section{Citra Restoran}

Citra merupakan seperangkat keyakinan, ide dan kesan yang dimiliki oleh seseorang terhadap suatu objek (Kotler dan Armstrong, 2012). Citra (image) dapat dikemukakan dalam berbagai konteks yang berkaitan dengan objek dari citra tersebut seperti citra perusahaan (corporate image), citra merek (brand image), citra toko (store image) dan sebagainya (Pradhana et al., 2017).
Citra restoran (restaurant image) didefinisikan sebagai penilaian menyeluruh pelanggan terhadap atribut-atribut yang menonjol dari restoran (Ryu, et al, 2008).Citra restoran adalah persepsi konsumen atas restoran berdasarkan atribut yang relevan dari restoran tersebut (Agu, et al, 2017).

Image restoran sangat penting di mata konsumen, karena restoran yang memiliki image buruk di mata konsumen maka dikuatirkan akan membuat nama restoran akan menyebar melalui mulut ke mulut yang negatif (negative word of mouth). Sebaliknya, jika konsumen memiliki image yang baik akan suatu restoran, maka akan menjadi sebuah "nilai lebih" di mata konsumennya, dan jika restoran mempunyai citra yang baik, dipercaya konsumen pun dapat memberikan rekomendasi yang positif ke orang lain (positive word of mouth), karena konsumen puas dengan apa yang diperolehnya.

\section{Niat Berperilaku}

Niat berperilaku terhadap produk merupakan hasil dari proses kepuasan yang dirasakan konsumen terhadap produk yang telah diberikan oleh penyedia produk. Niat berperilaku merupakan kemauan untuk 
merekomendasikan layanan kepada orang lain dan kemauan untuk melakukan pembelian ulang (Hutama dan Subagio, 2014). Niat berperilaku (behavioral intentions) adalah kesadaran seseorang untuk mendorong upaya menampilkan perilaku tertentu dengan tujuan-tujuan yang dibentuk dari evaluasi personal dan konstruksi normatif (Goode dan Harris, 2007). Niat berperilaku adalah suatu proporsi yang menghubungkan diri dengan tindakan yang akan datang (Olson dan Peter, 2013). Niat berperilaku adalah frekuensi pembelian atau proporsi pembelian total dari pembeli yang setia terhadap merek tertentu (Schiffman dan Kanuk, 2010). Sehingga niat berperilaku pada konsumen restoran didefinisikan sebagai suatu kecenderungan atau kemungkinan yang akan dilakukan untuk kembali membeli, merekomendasikan restoran pada keluarga, saudara, teman kerja, kolega di masa depan (Ryu, et al, 2012).

Dapat disimpulkan bahwa niat berperilaku adalah kecenderungan konsumen untuk mengulang kembali atau tidak terhadap layanan yang dilakukan oleh pihak produsen. Niat berperilaku dapat ditunjukkan dari niat perilaku positif seperti keinginan untuk mengulangi pembelian, menyebarkan positive word of mouth, dan kesediaan merekomendasikan kepada orang lain. Niat berperilaku juga dapat ditunjukkan dari niat perilaku negatif seperti mengadu, berpindah atau berhenti membeli.

\section{Hipotesis}

Hipotesis yang dikembangkan dalam penelitian ini adalah:

$\mathrm{H}_{1}$ : Inovasi konsumen berpengaruh terhadap ucapan terima kasih

$\mathrm{H}_{2}$ : Inovasi konsumen berpengaruh terhadap kewajaran harga

$\mathrm{H}_{3}$ : Inovasi konsumen berpengaruh terhadap citra restoran yang inovatif.

$\mathrm{H}_{4}$ : Ucapan terima kasih berpengaruh terhadap kewajaran harga.

$\mathrm{H}_{5}$ : Citra restoran berpengaruh terhadap kewajaran harga.

$\mathrm{H}_{6}$ : Rasa terima kasih berpengaruh terhadap niat berperilaku

$\mathrm{H}_{7}$ : Kewajaran harga berpengaruh terhadap niat berperilaku

$\mathrm{H}_{8}$ : Citra restoran berpengaruh terhadap niat berperilaku

\section{METODE PENELITIAN}

\section{Populasi dan Sampel}

Adapun objek penelitian ini aantara lain adalah berikut:

1. SFA Steak \& Resto Kampung Sewu, J1 R.E. Martadinata 286 Surakarta. 
2. SFA Steak \& Resto Klodran, Jl Adi Sumarmo, Klodran, Surakarta.

3. SFA Steak \& Resto MakamHaji, J1 Slamet Riyadi 414, Makamhaji, Kartasura.

4. SFA Steak \& Resto Solobaru, J1. Ir. Soekarno, Grogol, Sukoharjo.

Populasi adalah sekumpulan individu, peristiwa, atau hal yang menarik yang ingin diteliti; dan sampel adalah subset populasi yang terdiri dari anggota populasi yang terpilih (Sekaran, 2006). Populasi penelitian ini adalah konsumen SFA Steak dan Resto di wilayah Surakarta, yaitu SFA Steak \& Resto Kampung Sewu, Klodran, Makam Haji dan Solo Baru. Ferdinand (2014) menyatakan ukuran sampel yang diambil tergantung pada jumlah indikator yang digunakan dalam variabel laten, yaitu 5-10 kali jumlah indikator. Sampel ditentukan sebanyak 130 (5 x 26 indikator), yaitu konsumen yang sedang melakukan pembelian di SFA
Steak \& Resto Surakarta, dengan metode convenience sampling.

\section{Pengumpulan dan Analisis Data}

Sumber data dalam penelitian ini menggunakan data primer dan data sekunder. Pengumpulan data menggunakan kuesioner. Instrumen penelitian diukur dengan skala likert, menggunakan 5 (lima) poin dari sangat tidak setuju sampai dengan sangat setuju. Pengujian validitas digunakan Confirmatory Factor Analysis (CFA). Indikator merupakan indikator pengukur konstruk, harus memiliki nilai loading factor > 0,50 (Hair et al., 2010). Pengujian reliabilitas menggunakan Cronbach Alpha. Suatu konstruk dikatakan reliabel jika Cronbach Alpha > 0,60 (Nunnally, dalam Ghozali 2011). Analisis data menggunakan Structural Equation Modelling (SEM) program Amos. Dalam analisis SEM harus dipenuhi asumsi sebagai berikut:

Tabel 1. Goodness of Fit Index

\begin{tabular}{lll}
\hline No & Goodness of Fix Index & \multicolumn{1}{c}{ Cut of Value } \\
\hline 1 & Chi-Square & Diharapkan Kecil \\
2 & Signifikansi & $\geq 0,05$ \\
3 & RMSEA & $\leq 0,08$ \\
4 & GFI & $\geq 0,90$ \\
5 & AGFI & $\leq 0,90$ \\
6 & CMIN/ DF & $\leq 2,00$ \\
7 & TLI & $\geq 0,95$ \\
8 & CFI & $\geq 0,94$ \\
\hline
\end{tabular}

Sumber: Ferdinand (2014)

Definisi operasional variabel yang Inovasi konsumen adalah digunakan adalah: kecenderungan konsumen SFA Steak

1. Inovasi Konsumen \& Resto untuk memberikan ide atau 
mencoba produk-produk baru yang dikeluarkan oleh SFA Steak \& Resto. Indikator inovasi konsumen berdasarkan penelitian Jin, et al. (2016) terdiri dari:

a. Mencoba menu terbaru

b. Mengetahui nama menu makanan baru

c. Mengetahui menu terbaru dibanding orang lain

d. Mencoba menu lain

e. Inovasi menu

2. Ucapan Terima Kasih

Ucapan berterima kasih adalah sentimen positif yang diungkapkan oleh konsumen atas suatu tindakan yang dilakukan oleh SFA Steak \& Resto di wilayah Surakarta dan sekitarnya telah menguntungkannya. Indikator ucapan terima kasih berdasarkan penelitian Jin, et al (2016) terdiri dari:
a. Bersyukur
b. Senang
c. Menghargai pelayanan
d. Ucapan terima kasih

3. Kewajaran Harga

Kewajaran harga adalah sejumlah uang yang dibayarkan oleh konsumen SFA Steak \& Resto di wilayah Surakarta dan sekitarnya atas pelayanan dan menu makanan yang diperoleh konsumen. Indikator kewajaran harga berdasarkan penelitian Jin et al. (2016) terdiri dari:
a. Harga makanan
b. Harga minuman
c. Harga sesuai layanan
d. Harga sesuai kondisi keuangan konsumen

4. Harga sesuai kondisi keuangan konsumen citra restoran yang inovatif Citra restoran yang inovatif adalah persepsi konsumen terhadap inovasi yang dilakukan oleh SFA Steak \& Resto dalam meningkatkan citranya. Indikator citra restoran yang inovatif berdasarkan penelitian Jin, et al (2016) terdiri dari:

a. Jenis menu

b. Pelopor inovasi menu baru

c. Ide baru dalam inovasi menu

d. Pemberian promosi dan potongan harga

e. Inovasi teknologi

5. Niat Berperilaku

Niat Berperilaku adalah kecenderungan konsumen SFA Steak \& Resto untuk mengulang kembali atau tidak terhadap layanan yang dilakukan oleh pihak restoran. Indikator behavioural intention berdasarkan penelitian Jin,et al (2016) yang terdiri dari:

a. Keinginan konsumen kembali di lain waktu

b. Keinginan datang kembali dalam waktu dekat

c. Merekomendasikan ke orang lain

d. Konsumen menyatakan hal positif tentang restoran 


\section{HASIL DAN PEMBAHASAN}

\section{Karakteristik Responden}

Tabel 2. Karakteristik Responden

\begin{tabular}{|c|c|c|c|c|}
\hline No & Berdasarkan & & Frekuensi (orang) & Persentase $(\%)$ \\
\hline \multirow[t]{3}{*}{1} & Jenis Kelamin & Pria & 58 & 44,6 \\
\hline & & Wanita & 72 & 55,4 \\
\hline & & Total & 130 & 100,0 \\
\hline \multirow[t]{4}{*}{2} & Usia & $<35$ tahun & 27 & 20,8 \\
\hline & & $35-45$ tahun & 65 & 50,0 \\
\hline & & $>45$ tahun & 38 & 29,2 \\
\hline & & Total & 130 & 100,0 \\
\hline \multirow[t]{5}{*}{3} & Pendidikan & SMA & 61 & 46,9 \\
\hline & terakhir & Akademi/Diploma & 33 & 25,4 \\
\hline & & Strata 1 & 28 & 21,5 \\
\hline & & Strata 2 & 8 & 6,2 \\
\hline & & Total & 130 & 100,0 \\
\hline \multirow[t]{7}{*}{4} & Pekerjaan & Pelajar/mahasiswa & 17 & 13,1 \\
\hline & & TNI/Polri & 14 & 10,8 \\
\hline & & PNS & 24 & 18,5 \\
\hline & & Profesional & 21 & 16,2 \\
\hline & & Swasta & 22 & 16,9 \\
\hline & & Wiraswasta & 32 & 24,6 \\
\hline & & Total & 130 & 100,0 \\
\hline
\end{tabular}

Sumber : Data primer yang diolah, 2018

\section{Uji Instrumen Penelitian}

Hasil pengujian validitas dengan menggunakan confirmatory factor analysis (CFA), menunjukkan nilai estimate $>0,50$ sehingga instrumen penelitian layak digunakan. Sedang pengujian reliabilitas, hasil uji menunjukkan bahwa seluruh pada tabel berikut: konstruk (inovasi konsumen, ucapan terima kasih, kewajaran harga, citra restoran, niat berperilaku) mempunyai cronbach's alpha >0,60; sehingga dinyatakan reliabel. Hasil pengujian reliabilitas tersaji

Tabel 3. Hasil Uji Reliabilitas

\begin{tabular}{lc}
\hline \multicolumn{1}{c}{ Konstruk } & Cronbach`s Alpha \\
\hline Inovasi Konsumen & 0,728 \\
Terima Kasih & 0,853 \\
Kewajaran Harga & 0,679 \\
Citra Restoran & 0,753 \\
Niat Berperilaku & 0,658 \\
\hline
\end{tabular}

Sumber: Data primer diolah, 2018 


\section{Pengujian Goodness of Fit}

Evaluasi goodness of fit dimaksudkan untuk menilai seberapa baik model penelitian yang dikembangkan. dievaluasi tingkat goodness of fit. Pengujian goodness of fit ditunjukkan dalam tabel berikut:

Pada tahap ini kesesuaian model penelitian

Tabel 4. Hasil Uji Goodness of Fit Index

\begin{tabular}{llrl}
\hline \multicolumn{1}{c}{ GFI Index } & Cut-Off Value & Hasil Uji & Evaluasi Model \\
\hline Chi-Square & $\chi^{2}$ mendekati nol & 231,921 & - \\
Probabilitas & $\geq 0,05$ & 0,067 & Good fit \\
GFI & $\geq 0,90$ & 0,871 & Marjinal \\
AGFI & $\geq 0,90$ & 0,837 & Marjinal \\
TLI & $\geq 0,95$ & 0,949 & Good fit \\
CFI & $\geq 0,95$ & 0,955 & Good fit \\
RMSEA & $\geq 0,08$ & 0,035 & Good fit \\
CMIN/DF & $\leq 2,0$ & 1,154 Good fit \\
\hline
\end{tabular}

Sumber: Data primer yang diolah, 2019

Model struktural menunjukkan nilai chisquare pada full model sebesar 231,921. Nilai TLI, CFI, RMSEA, CMIN/DF menunjukkan good fit sesuai kriteria yang disyaratkan; nilai AGFI, GFI menunjukkan marjinal, sehingga model layak dan fit untuk digunakan.

\section{Pengujian Model Struktural}

Pengujian model struktural pada analisis SEM, diperoleh hasil sebagai berikut:

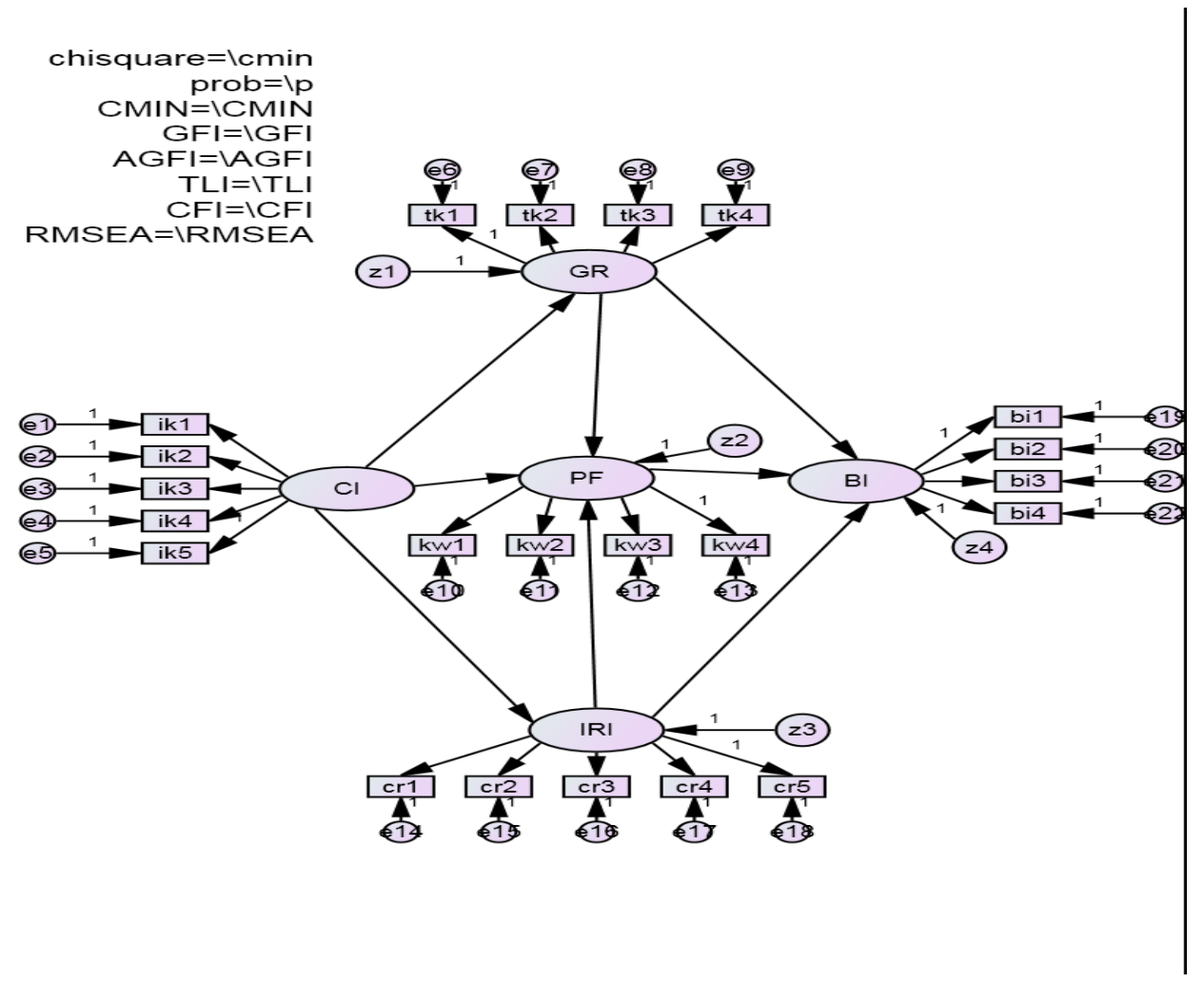

Gambar 1. Hasil analisis SEM 
Pengujian Hipotesis Penelitian

dengan menganalisis nilai critical ratio

Pengujian hipotesis dengan $(\mathrm{CR})>1,96$ dan nilai probability $(\mathrm{p})<$ menganalisis nilai regresi (regression weights analysis). Pengujian hipotesis ini

0,05 . Hasil analisis regression weights ditunjukkan tabel berikut:

Tabel 5. Hasil Regression Weights

\begin{tabular}{|c|c|c|c|c|c|c|}
\hline & & Estimate & S.E. & C.R. & $\bar{P}$ & Label \\
\hline GR & $<---\quad$ CI & .304 & .137 & 2.220 & .026 & Signifikan \\
\hline PF & $<---\quad$ CI & .095 & .180 & .529 & .597 & Tidak Signifikan \\
\hline IRI & $<---\quad C I$ & .491 & .126 & 3.884 & $* * *$ & Signifikan \\
\hline PF & $<---\quad$ GR & .291 & .108 & 2.700 & .007 & Signifikan \\
\hline $\mathrm{PF}$ & $<---\quad$ IRI & .454 & .218 & 2.084 & .037 & Signifikan \\
\hline BI & $<---\quad$ GR & .170 & .079 & 2.144 & .032 & Signifikan \\
\hline BI & $<---\quad P F$ & .094 & .105 & .887 & .375 & Tidak Signifikan \\
\hline BI & $<---\quad$ IRI & .281 & .129 & 2.180 & .029 & Signifikan \\
\hline
\end{tabular}

Sumber: Data primer yang diolah, 2019

Dari hasil pengujian hipotesis, dapat dijelaskan sebagai berikut:

1. Pengaruh inovasi konsumen terhadap ucapan terima kasih

Hasil pengujian diperoleh nilai $\mathrm{CR}$ $2,220>1,96$ dan nilai p $0,026<0,05$ maka terdapat pengaruh inovasi konsumen terhadap ucapan terima kasih, sehingga hipotesis 1 didukung. Temuan menunjukkan bahwa konsumen yang inovatif cenderung lebih terbuka dengan adanya hal yang baru. Hasil ini mendukung penelitian dari Jin, Line dan Markebu (2016) dengan hasil bahwa inovasi konsumen berpengaruh terhadap ucapan terima kasih. Bin (2013) menyatakan bahwa konsumen yang inovatif selalu memiliki kebutuhan baru untuk menambah pengalaman barunya, sehingga konsumen yang inovatif akan menghargai penawaran yang inovatif dan memberikan rasa terima kasih kepada perusahaan yang menyediakan produk dan layanan kreatif yang memenuhi kebutuhan ini.

2. Pengaruh inovasi konsumen terhadap kewajaran harga

Hasil pengujian diperoleh nilai $\mathrm{CR}$ $0,529<1,96$ dan nilai p $0,597>0,05$ maka tidak ada pengaruh inovasi konsumen terhadap kewajaran harga, sehingga hipotesis 2 tidak didukung. Hasil ini mendukung penelitian dari Jin, Line dan Markebu (2016) dengan temuan bahwa inovasi konsumen tidak berpengaruh terhadap kewajaran harga. Hasil ini menunjukkan bahwa konsumen yang inovatif terhadap menu baru cenderung tidak mempermasalahkan harga yang ditetapkan oleh pihak restoran karena 
yang terpenting baginya adalah dengan mencoba menu baru makan akan memiliki pengalaman baru tentang produk makanan yang dikonsumsinya.

3. Pengaruh inovasi konsumen terhadap citra restoran yang inovatif Hasil pengujian diperoleh nilai $\mathrm{CR}$ $3,884>1,96$ dan nilai $\mathrm{p} 0,00<0,05$ maka terdapat pengaruh inovasi konsumen terhadap citra restoran, sehingga hipotesis 3 didukung.

Hal ini sesuai dengan penelitian Jeong dan Jang (2011) yang menyatakan bahwa inovasi konsumen berdampak positif dalam mendorong citra restoran yang inovatif. Bin (2013) menyatakan bahwa konsumen yang inovatif digerakkan oleh motivasi intrinsik untuk mencari produk baru dan apabila produk yang disajikan sesuai maka konsumen akan menyampaikaninformasi tentang pengalaman yang memuaskan dalam jejaring sosial mereka yaitu ketika produk baru memuaskankebutuhan dan pengalaman barudari konsumen yang inovatif mungkinuntuk mempromosikan produk dalam jejaring sosial mereka.

4. Pengaruh ucapan terima kasih terhadap kewajaran harga
Hasil pengujian diperoleh nilai $\mathrm{CR}$ $2,700>1,96$ dan nilai p $0,07<0,05$ maka terdapat pengaruh ucapan terima kasih terhadap kewajaran harga, sehingga hipotesis 4 didukung. Hasil ini mendukung penelitian Jin, Line dan Markebu (2016) dengan hasil bahwa rasa terima kasih berpengaruh terhadap kewajaran harga. Soscia (2007) menyatakan bahwa ucapan terima kasih dapat memicu emosi positif dan perilaku yang menguntungkan, dimana rasa terima kasih akan menimbulkan persepsi bahwa harga itu wajar. Hal ini berarti pihak restoran perlu mengucapkan terima kasih kepada konsumen yang telah berkunjung dan membeli produk dari restoran, hal ini berfungsi agar dapat menekan perasaan dari konsumen terhadap harga yang ditetapkan oleh pihak restoran.

5. Pengaruh citra restoran yang inovatif terhadap kewajaran harga

Hasil pengujian diperoleh nilai CR $2,084>1,96$ dan nilai p $0,037<0,05$ maka terdapat pengaruh citra restoran yang inovatif terhadap kewajaran harga, sehingga hipotesis 5 didukung. Hasil ini mendukung penelitian Jin, Line dan Markebu (2016) bahwa citra restoran yang inovatif berpengaruh terhadap 
kewajaran harga. Hal ini berarti citra restoran yang inovatif dalam membuat menu baru, menjaga lingkungan fisik retoran ataupun memberikan pelayanan yang baik akan membuat konsumen merasa wajar terhadap harga yang ditetapkan oleh pihak restoran, hal tersebut karena pada dasarnya tujuan konsumen ke restoran adalah membeli produk yang sesuai kemampuannya dan disesuaikan dengan cita rasa produk yang diharapkannya (Heo dan Wang, 2013). Konsumen yang inovatif menganggap bahwa harga yang wajar adalah apabila konsumen puas terhadap inovasi yang dilakukan restoran.

6. Pengaruh ucapan terima kasih terhadap niat berperilaku

Hasil pengujian diperoleh nilai CR $2,144>1,96$ dan nilai p $0,032<0,05$ maka terdapat pengaruh ucapan terima kasih terhadap niat berperilaku, sehingga hipotesis 6 didukung.

Hasil ini mendukung penelitian Jin, Line dan Markebu (2016) bahwa ucapan terima kasih berpengaruh terhadap niat berperilaku. Kim dan Lee (2013) juga menyatakan bahwa rasa terima kasih berhubungan dengan niat untuk membeli sehingga terjadi hubungan timbal balik yang menguntungkan antara konsumen dengan pihak restoran. Hal ini menunjukkan bahwa rasa terima kasih adalah prediktor signifikan dari niat perilakudi restoran karena dengan bentuk ucapan terima kasih yang diberikan oleh pihak restoran dapat membuat konsumen merasa lebih diperhatikan sehingga tertarik untuk datang kembali ke restoran.

7. Pengaruh kewajaran harga terhadap niat berperilaku

Hasil pengujian diperoleh nilai CR $0,887<1,96$ dan nilai $\mathrm{p} 0,375>0,05$ maka tidak ada pengaruh kewajaran harga terhadap niat berperilaku, sehingga hipotesis 7 tidak didukung. Hasil ini mendukung penelitian Jin, Line dan Markebu (2016) bahwa kewajaran harga tidak berpengaruh terhadap niat berperilaku. Konsumen terkadang tidak mempertimbangkan masalah harga untuk dapat berperilaku membeli, hal ini dikarenakan ada beberapa faktor lain seperti cita rasa produk ataupun kualitas pelayanan serta suasana restoran yang membuat konsumen memiliki keinginan untuk membeli kembali.

8. Pengaruh citra restoran yang inovatif terhadap niat berperilaku

Hasil pengujian diperoleh nilai CR $2,80>1,96$ dan nilai $\mathrm{p} 0,029<0,05$ maka terdapat pengaruh citra restoran 
yang inovatif terhadap niat berperilaku, sehingga hipotesis 8 didukung. Hasil ini mendukung penelitian Jin, Line dan Markebu (2016) bahwa citra restoran yang inovatif berpengaruh terhadap niat berperilaku.Hyan dan Kang (2014) menyatakan bahwa kepuasan konsumen terhadap lingkungan restoran yang kreatifdapat berpengaruh pada pada niat berperilaku. Hasil penelitian ini menunjukkan bahwa restoran yang inovatifdapat memunculkan sikap ataupun emosi positif pada konsumen sehingga dapat membentuk niat berperilaku dari konsumen untuk membeli di restoran tersebut.

\section{KESIMPULAN}

Hasil penelitian menunjukkan bahwa inovasi konsumen, berpengaruh ucapan terima kasih dan citra restoran yang inovatif tetapi tidak berpengaruh terhadap kewajaran harga. Ucapan terima kasih berpengaruh terhadap kewajaran harga dan niat berperilaku. Citra restoran yang inovatif berpengaruh terhadap kewajaran harga dan niat berperilaku. Kewajaran harga tidak berpengaruh terhadap niat berperilaku. SFA Steak dan Resto perlu mempertimbangkan membuat menu-menu baru pada waktu-waktu tertentu agar semakin variatif pilihan konsumen, selain itu perlu menghimbau kepada karyawannya untuk mengucapkan terima kasih setelah memberikan pelayanan kepada konsumen. Selain itu SFA Steak \& Resto Surakarta juga perlu menjaga stabilitas harga mengingat persaingan di dunia kuliner sangat ketat, hal ini supaya konsumen tidak berpindah ke tempat lain.

\section{DAFTAR PUSTAKA}

Agu, Godswill., Kalu Innocent Ndu., Agaeze Chimaobi. 2017. "Fast Food Restaurant Image and Sustainable Customer Loyalty In A Period of Economic Recession". International Journal of Social Sciences and Humanities Reviews. Vol. 7 No. 2, pp. $1-10$.

Bin, G. 2013. A reasoned action perspective of user innovation: Model and empirical test. Industrial Marketing Management42 (4): 608619.

Choo, H. J., S. Y. Sim, H. K. Lee, and H. B. Kim. 2014. The effectof consumers' involvement and innovativeness on the utilization of fashion wardrobe. International Journal of Consumer Studies 38 (2): 175-182

Chung, J. Y., G. T. Kyle, J. F. Petrick, and J. D. Absher. 2011.Fairness of prices, user fee policy and willingness to payamong visitors to a national forest. Tourism Management 32(5), pp. 1038-1346

Daskalopoulou, I. 2008. Fairness perceptions and observed consumerbehavior: Results of a partial observability model. TheJournal of Socio-Economics Vol 3 (7), pp. 31-44. 
Dhurup, M., Mafini, C \& Dumasi, T. 2014. The impact of packaging, price, and brand awareness on brand loyalty: Evidence from the paint retailing industry, " Acta Commercii 14 (1), pp. 212-225.

Diller, H. 2008. Price Fairness. Journal of Product \& BrandManagement. Vol 17 (5), pp. 353-355.

Englis, B. G., and D. M. Phillips. 2013. Does innovativeness drive environmentally conscious consumer behavior? Psychology \& Marketing. Vol 30 (2), pp. 160-172.

Fakhrudin, Arif. 2017. Analisis Pengaruh Consumer Innovativeness dan Market Maven Terhadap Opinion Leadership. Jurnal Manajemen dan Binsis. Vol 8, No 2, hal 142-162.

Ferdinand, A. 2014. Structural Equation Modeling Dalam Penelitian Manajemen. Fakultas Ekonomi Universitas Diponegoro. Semarang.

Grewal, D., D. M. Hardesty, and G. R. Iyer. 2004. The effectsof buyer identification and purchase timing on consumers'perceptions of trust, price fairness, and repurchase intentions.Journal of Interactive Marketing. Vol 18 (4): pp. 87-100.

Hartini, Sri. 2011. Pengembangan Model TAM: Expertice Dan Innovativeness Sebagai Variabel Moderator Studi pada Penggunaan E Banking. Journal of Business and Banking. Vol 1, No. 2, hal 155- 164.

Heo, C. Y., V. der Rest, and X. L. Wang. 2013. Cultural influenceson fairness perception of revenue management pricing in the tourism and hospitality industry. In The 11th Asia Pacific CHRIE Conference

Homburg, C., D. Totzek, and M. Kramer. 2014. How price complexity takes its toll: The neglected role of a simplicity bias and fairness in price evaluations. Journal of BusinessResearch 67 (6), pp. 11141122.
Hutama, Christanto Leoma dan Hartono Subagio. 2014. Analisa Pengaruh Dining Experience terhadap Behavioral Intention dengan Customer Satisfaction sebagai Variabel Intervening (Studi Kasus: Domicile Kitchen and Lounge). Jurnal Manajemen Pemasaran Petra. Vol. 2 (1), hal . 1-8.

Hwang, J., and S. S. Hyun. 2013. The impact of nostalgia triggerson emotional responses and revisit intentions in luxury restaurants:The moderating role of hiatus. International Journal of Hospitality Management. Vol 3 (3), pp. 250262.

Hyun, S. S., and J. Kang. 2014. A better investment in luxury restaurants: Environmental or non-environmental cues? International Journal of Hospitality Management Vol 3 (9), pp. :57-70.

Jang, S., and Y. Namkung. 2009. Perceived quality, emotions, andbehavioral intentions: Application of an extended Mehrabian-Russell model to restaurants. Journal of Business Research. Vol 62(4), pp. 451-60.

Jeong, E., and S. S. Jang. 2011. Restaurant experiences triggeringpositive electronic word-of-mouth (eWOM) motivations. International Journal of Hospitality Management.Vol 30 (2), pp. 356-366.

Jin, (Paul), Naehyun, Ben Goh, Lynn Huffman and Jingxue Jessica Yuan. 2015. Predictors and Outcomes of Perceived Image of Restaurant Innovativeness in Fine-Dining Restaurants. Journal of Hospitality Marketing \& Management. Vol 24 (5), pp. 457-485.

Kim, S., and J. S. Lee. 2013. Is satisfaction enough to ensure reciprocity with upscale restaurants? The role of gratitude relative to satisfaction. International Journal of Hospitality Management. Vol 3 (3), pp. 118-128. 
Kukar-Kinney, M., L. Xia, and K. B. Monroe. 2007. Consumers'perceptions of the fairness of price-matching refund policies.Journal of Retailing. Vol 83 (3), pp. 325-337.

Lane, C. 2013. Taste makers in the "finedining" restaurant industry:The attribution of aesthetic and economic value by gastronomicguides. Poetics 41 (4): 342-365.

Nazari, M., Hosseini, M.A.S., and Kalejahi, S.V.T (2014) Impact of Price Fairness on PriceSatisfaction, Customer Satisfaction and Customer Loyalty in Iran TelecommunicationMarket (Case: MTN Irancell Company), Asian Journal of Research in Marketing. Vol.3,No.1,pp. 131-144.

Mathews, M. A., and N. J. Shook. 2013. Promoting or preventing thanks: Regulatory focus and its effect on gratitude and indebtedness.Journal of Research in Personality. Vol 47 (3), pp. 191-195.

Pei, Z., A. Paswan, and R. Yan. 2014. Etailer's return policy,consumer's perception of return policy fairness and purchaseintention. Journal of Retailing and Consumer Services. Vol 21 (3), 249-257.

Peter, J. Paul dan Jerry C. Olson. 2013. Perilaku Konsumen dan Strategi Pemasaran. (Alih Bahasa:Damos Sihombing). Salemba Empat. Jakarta.

Pradhana, Rachmawan Rony., Alwi Suddin dan Suprihatmi Sri Wardiningsih. 2017. "Pengaruh Citra Restoran terhadap Behavioral Intention dengan Kepuasan Pelanggan sebagai Variabel Mediasi (Survei pada Pelanggan Restoran di Seluruh Wilayah Kabupaten Karanganyar)". Jurnal Manajemen Sumber Daya Manusia. Vol. 11 No. 2, hal. $251-265$.

Ryu, K., Han, H., and Kim, T.H., 2008. The Relationships Among Overall
Quick-CasualRestorant Image, Perceived Value, Customer Satisfaction, and BehavioralIntention.International Journal of Hospitality Management, Vol. 27, pp. 459-469.

Ryu, K., Lee, HR and Kim, Woo Gon. 2012. The influence of the quality of the physical environment, food, and service on restaurant image, customer perceived value, customer satisfaction, and behavioral intentions. International Journal of Contemporary Hospitality Management. Vol. 24 Issue: 2, pp.200-223.

Schiffman, Leon. G dan Leslie, Kanuk. 2010. Perilaku Konsumen. (Alih Bahasa Zoelkifli Kasip.PT. Indeks. Jakarta.

Sekarsari, Larasati Ayu. 2018. Hubungan antara Restaurant Image, Perceived Value, Customer Satisfaction,dan Behavioral Intention. Kinerja. Vol 15 No 2, hal 108-119.

Setyanta, Budi. 2018. Peran Involvement Sebagai Variabel Pemoderasi Model Loyalitas Pelanggan. Jurnal Ekonomi Bisnis dan Kewirausahaan. Vol. 7 No. 1, 33-57.

Sugiama. A. Gima. 2017. Pengaruh Kemasan, Kewajaran Harga dan Brand Awareness terhadap Brand Loyalty (Studi Kasus pada Wisatawan Nusantara di Kartika Sari Bandung). Jurnal Manajemen Maranatha, Program Studi Manajemen, Fakultas Ekonomi, Universitas Kristen Maranatha. Vol 17, No 1, hal 1-14.

Sukarmen, Putu, Andi Sularso dan Deasy Wulandari. 2013. Analisis Pengaruh Inovasi Produk terhadap KepuasanKonsumen dengan Keunggulan Bersaing Sebagai VariabelIntervening Pada Produk Gula Pasir Sebelas (Gupalas)Pabrik Gula Semboro PTP Nusantara XI (Persero). Jeam. Vol 12 No 1, hal 63-79. 
Xia, L., and K. B. Monroe. 2010. Is a good deal always fair?Examining the concepts of transaction value and price fairness.Journal of Economic Psychology 31 (6), pp. 884-894.

Yun, W., and C. Hira. 2012. The effect of fashion innovativeness on consumer's online apparel customization. InternationalJournal of Organizational Innovation. Vol 5 (2), pp. 263-283. 